\title{
An effective adsorbent developed from municipal solid waste and coal co-combustion ash for $\mathrm{As}(\mathrm{V})$ removal from aqueous solution
}

\author{
Yun Fan ${ }^{\mathrm{a}, \mathrm{b}}$, Fu-Shen Zhang ${ }^{\mathrm{a}, *}$, Yinan Feng ${ }^{\mathrm{c}}$ \\ a Research Center for Eco-Environmental Sciences, Chinese Academy of Sciences, 18 Shuangqing Road, Beijing 100085, China \\ ${ }^{\mathrm{b}}$ Graduate University of Chinese Academy of Sciences, Beijing 100039, China \\ ${ }^{\mathrm{c}}$ Zhengzhou Municipal Administration Bureau, Zhengzhou, Henan Province 450000, China
}

\section{A R T I C L E I N F O}

\section{Article history:}

Received 9 November 2007

Received in revised form 21 January 2008

Accepted 11 February 2008

Available online 16 February 2008

\section{Keywords:}

Municipal solid waste

Co-combustion ash

Arsenic

Iron-impregnation

Ultrasound irradiation

\begin{abstract}
A B S T R A C T
A new adsorbent was developed from waste ash resulting from municipal solid waste and coal cocombustion power plant. The ash was firstly subjected to hydrothermal treatment for zeolite synthesis, and then modified with iron(II) ions by agitation (ISZ) or ultrasonic (UISZ) treatment. The effect of operating factors such as $\mathrm{pH}$, contact time, initial $\mathrm{As}(\mathrm{V})$ concentration and adsorbent dosage was investigated and the optimum operating conditions were established. The adsorption capacity for $\mathrm{As}(\mathrm{V})$ onto UISZ and ISZ were 13.04 and $5.37 \mathrm{mgg}^{-1}$, respectively. The adsorption isotherm data could be well described by Langmuir isotherm model. The optimum initial $\mathrm{pH}$ values for $\mathrm{As}(\mathrm{V})$ removal were 2.5 and $2.5-10.0$ by ISZ and UISZ, respectively. The results indicated that ultrasound treatment scattered the particles of the adsorbent uniformly, which was in favor of impregnating iron ions into pores. Leaching of hazardous elements from the used adsorbents was very low. Accordingly, it is believed that the adsorbents developed in this study are environmentally acceptable and industrially applicable for utilization in arsenic-containing wastewater treatment.
\end{abstract}

(C) 2008 Elsevier B.V. All rights reserved.

\section{Introduction}

Arsenic has been known as a common and notorious contaminant in water environment. Long-term exposure to arsenic contaminated water may lead to cancers of the skin, lung and other organs [1]. Although environmental regulations have limited the production of arsenic and its compounds, they are still extensively used in metallurgy, agriculture, forestry, electronics, pharmaceuticals and glass and ceramic industry. According to China EPA for integrated wastewater discharge standard, the tolerance limit for arsenic is $0.5 \mathrm{mg} \mathrm{l}^{-1}$ for the effluents discharge into inland surface water [2]. The chemistry of arsenic is interestingly complex. The oxyanions of arsenic exist in four different arsenate species as $\mathrm{H}_{3} \mathrm{AsO}_{4}, \mathrm{H}_{2} \mathrm{AsO}_{4}{ }^{-}, \mathrm{HAsO}_{4}{ }^{2-}$ and $\mathrm{AsO}_{4}{ }^{3-}$ in the $\mathrm{pH}$ range $<2.0$, $2.0-7.0,7.0-12.0$ and $>12.0$, respectively [3].

The removal of arsenic from aqueous solution has become increasingly important and therefore, an appropriate treatment and measures need to be employed to the polluted water to attain the required environmental standard. In recent years many approaches have been developed, including adsorption, ion exchange, reverse osmosis, nanofiltration, coagulation process, membrane permeation, biological methods and photocatalytic oxidation [4-11].

\footnotetext{
* Corresponding author. Tel.: +86 10 62849515; fax: +861062849515.

E-mail address: fszhang@rcees.ac.cn (F.-S. Zhang).
}

Among those methods, NF/RO and adsorption are highly efficient and economical techniques. Various adsorption materials have been used such as activated carbon, activated alumina, iron hydroxides and lanthanum compounds [12-15]. According to previous studies, hydrated iron(II-III) has a high affinity toward arsenic oxyanions and it is very selective in the sorption process [16]. However, most iron oxides are only available as fine powders and are difficult to separate from aqueous solution after adsorption activity. Because of this, recent researches have focused on creating cheap and stable iron-bearing support media including sand [17], activated carbon [18], and municipal solid waste (MSW) melted slag [19].

In a previous study, we found that waste ash from power plant fueled with MSW and coal was good material for the synthesis of high quality zeolite [20]. The product was generally with higher cation exchange capacity values and B.E.T. surface area compared with other sources of zeolites. MSW, in China, generally has the properties of low heat value (approx. $4200 \mathrm{~kJ} \mathrm{~kg}^{-1}$ ) and high water content since it is collected without separating into burnable and unburnable matters, thus needs coal addition for effective combustion in the power plants. In recent years, co-combustion of MSW with coal has been greatly encouraged by the Chinese government. Accordingly, large amount of co-combustion ash is generated. Currently, most of the ash is disposed by landfill and only a small amount is used as an ingredient in cement and other construction products. 
The main objective of this research was to develop a new approach for effective utilization of the special type of waste ash. The effectiveness of the ash-derived zeolites for arsenic removal from aqueous solution was investigated. In particular, to improve its sorption selectivity for arsenic oxyanions the synthesized products modified with ferrous salt was also performed.

\section{Materials and methods}

\subsection{Materials}

Waste ash was sampled from a power plant fueled with municipal solid waste and coal located in northern China. The plant has two 24 h-run fluidized-bed incinerators with MSW disposal ability of 1000 tonnes perday, where electricity generation is 36 thousand $\mathrm{kWh}^{-1}$. The raw ash (MSWCA) was passed through an 80 -mesh sieve, dried at $105^{\circ} \mathrm{C}$ for $24 \mathrm{~h}$ and stored in a desiccator for use. The chemical compositions of the fly ash are $\mathrm{SiO}_{2}(45.50 \%)$, $\mathrm{Al}_{2} \mathrm{O}_{3}$ (22.60\%), $\mathrm{CaO}$ (6.29\%) and $\mathrm{Fe}_{2} \mathrm{O}_{3}$ (3.45\%). The mineralogical compositions of the ash were mainly Quartz, Gismondine, Hematite and Anorthite. The data have been given in detail by previous report [20].

\subsection{Zeolite synthesis}

Hydrothermal treatment was performed for the zeolite synthesis. Specifically, $5 \mathrm{~g}$ waste ash was mixed with $50 \mathrm{ml} 1.2 \mathrm{M}$ $\mathrm{NaOH}$ solution, and then the mixtures were transferred into $100 \mathrm{ml}$ Teflon-lined stainless autoclave followed by an aging process with vigorous shaking at room temperature for $24 \mathrm{~h}$. The mixtures were then crystallized under static conditions at $120^{\circ} \mathrm{C}$ for $10 \mathrm{~h}$. The solids were recovered by vacuum filtration, washed for several times with distilled water until the solution reached $\mathrm{pH} 10.0$ and dried overnight at $105^{\circ} \mathrm{C}$.

\subsection{Iron-impregnated zeolite}

The synthesized zeolite (SZ) (5g) was processed with $0.6 \mathrm{M}$ $\mathrm{FeSO}_{4} \cdot 7 \mathrm{H}_{2} \mathrm{O}(250 \mathrm{ml})$ by agitation for $24 \mathrm{~h}$ (ISZ) or ultrasonic treatment for $2 \mathrm{~h}$ and then agitated for $22 \mathrm{~h}$ (UISZ) in polyethylene containers $(500 \mathrm{ml})$ at $25 \pm 0.5^{\circ} \mathrm{C}$. Then the solid phase of samples was filtered off, washed with distilled water, dried in an oven at $105^{\circ} \mathrm{C}$.

\subsection{Arsenic sorption}

The adsorption experiments were carried out with batch method. A known amount of sorbent and $20 \mathrm{ml}$ of arsenate solution made from $\mathrm{Na}_{3} \mathrm{AsO}_{4} \cdot 12 \mathrm{H}_{2} \mathrm{O}$ were taken in a 50 -ml centrifuge tube. The $\mathrm{pH}$ was adjusted to the desired level with $0.1 \mathrm{M} \mathrm{NaOH}$ or $0.1 \mathrm{M}$ $\mathrm{HCl}$ solutions. The test tubes were then shaken for a fixed time at room temperature. After completing the reaction, suspensions were centrifuged and filtered through $25-\mathrm{mm} 0.45 \mu \mathrm{m}$ syringe filters and then analyzed for equilibrium $\operatorname{As}(\mathrm{V})$ concentration. The experimental parameters studied are $\mathrm{pH}$ (1.5-13.0), contact time (0.25-24 h), initial As(V) concentration (0.5-30 $\left.\mathrm{mg} \mathrm{l}^{-1}\right)$, adsorbent concentration $\left(0.1-2.5 \mathrm{gl}^{-1}\right)$, and the temperature was maintained at $25 \pm 0.5^{\circ} \mathrm{C}$.

\subsection{Toxicity characteristic leaching procedure (TCLP) test}

The TCLP provides a means of determining the potential for solid material to release chemical contaminants into a landfill environment [21]. The TCLP was applied to adsorbents after completion of the adsorption experiment (reaction conditions: initial $\mathrm{As}(\mathrm{V})=5 \mathrm{mgl}^{-1}$; sorbent dose $=0.5 \mathrm{gl}^{-1}$; contact time $=7 \mathrm{~h}$;

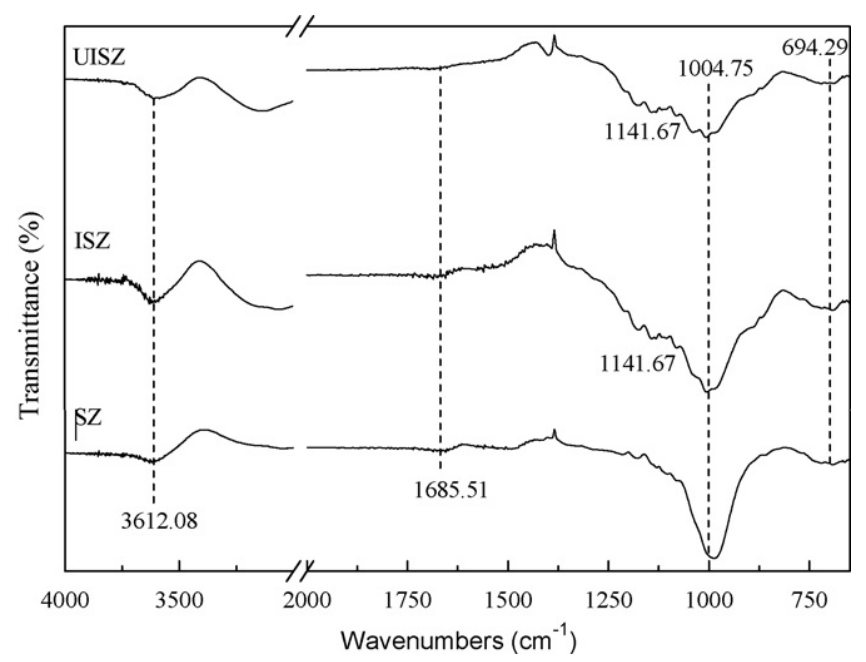

Fig. 1. FT-IR spectra of SZ, ISZ and UISZ.

$\mathrm{pH}=7.5$ ). Specifically, the spent adsorbent was extracted with extraction fluid $(5.7 \mathrm{ml}$ of acetic acid added to $500 \mathrm{ml}$ of doubledistilled water, plus $64.5 \mathrm{ml}$ of $1 \mathrm{moll}^{-1} \mathrm{NaOH}$ and diluted to 11 , $\mathrm{pH} 4.39 \pm 0.05$ ), with liquid/solid ratio of 20 . The extraction was achieved by shaking for $8 \mathrm{~h}$ and then laid aside for $16 \mathrm{~h}$, after which the liquid phase was separated off using $0.45 \mu \mathrm{m}$ cellulose acetate filter and analyzed for heavy metals by ICP-OES.

\subsection{Analytical methods}

The X-ray diffraction (XRD) patterns of SZ, ISZ and UISZ were obtained using a Philips X-ray diffractometer (Philips PW 1700, Holand). Operating conditions were $45 \mathrm{kV}$ and $250 \mathrm{~mA}$ using $\mathrm{Cu}$ $\mathrm{K} \alpha$ radiation. The samples were scanned from $10^{\circ}$ to $70^{\circ}$. Various crystalline phases present in the samples were identified with the help of JCPDS (Joint Committee on Powder Diffraction Standards) files for inorganic compounds.

The morphological structures of SZ, ISZ and UISZ were obtained by using scanning electron micrograph (SEM) (Hitachi S-3000N, Japan).

The supernatants were collected and determined by inductively coupled plasma optical emission spectrometer (ICP-OES) (PerkinElmer OPTIMA 2000, USA) or inductively coupled plasma mass spectrometers (ICP-MS) (VG Plasma Quard 3, UK). The arsenic detection limits for ICP-AES and ICP-MS were $80 \mu \mathrm{gl}^{-1}$ and $2 \mu \mathrm{g} \mathrm{l^{-1 }}$, respectively.

Fourier transform infrared spectrometry (FT-IR) (Nicolet Nexus670, USA) was used to analyze the functional groups in the adsorbent.

\section{Results and discussion}

\subsection{Characteristics of the adsorbent}

The FT-IR spectra of SZ, ISZ and UISZ are shown in Fig. 1. The weak bands at $694 \mathrm{~cm}^{-1}$ can be assigned to the external tetrahedral vibration [22]. The strong band at $1004 \mathrm{~cm}^{-1}$ corresponds to the asymmetric stretching of the $\mathrm{Si}-\mathrm{O}$ and $\mathrm{Al}-\mathrm{O}$ bonds [23]. The $\mathrm{O}-\mathrm{H}$ deformation vibration band is located at $1685 \mathrm{~cm}^{-1}$ [22]. The adsorption at $3612 \mathrm{~cm}^{-1}$ found in both the modified and unmodified zeolite is AlO-H stretch [24]. ISZ and UISZ presented an additional band at $1141 \mathrm{~cm}^{-1}$, which corresponds to vibration of $\mathrm{Fe}-\mathrm{O}[25]$.

The changes in morphology of SZ, ISZ and UISZ were observed by SEM. There were different in surface morphologies and particle 

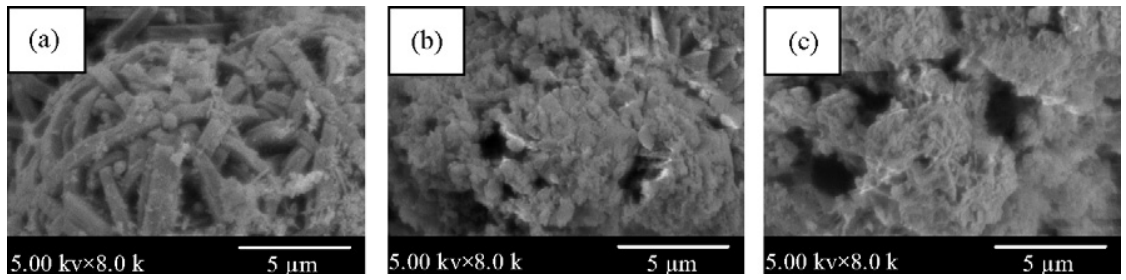

Fig. 2. SEM micrographs of SZ (a), ISZ (b) and UISZ (c).

size for the adsorbents (Fig. 2). The results of the XRD study (Fig. 3) showed that zeolite $\mathrm{P}\left(\mathrm{Na}_{3.6} \mathrm{Al}_{3.6} \mathrm{Si}_{2.4} \mathrm{O}_{32} \cdot 14 \mathrm{H}_{2} \mathrm{O}\right)$ was synthesized successfully through hydrothermal method.

In ultrasonic impregnation process, ultrasound intensified extremely the stir of $\mathrm{FeSO}_{4}$ solution, triggered drastically intermolecular collision in the liquid-solid system and brought about the cavitation effect [26]. All these facts strengthen the impregnation of iron ions into the carrier. Agitation and ultrasonic impregnation created a different surface morphology of the modified zeolite compared with the unmodified zeolite (Fig. 2). The ferric conversion films coated on the SZ could be clearly seen in the agitation and ultrasonic impregnation process. In addition, the particle size of UISZ ( $5 \mu \mathrm{m}$ ) was significant less than that of ISZ and SZ (over $10 \mu \mathrm{m})$. However, ultrasound irradiation had undetectable influence on the mineralogical composition of SZ. It was confirmed by XRD patterns of ISZ and UISZ that was similar to parent SZ (Fig. 3).

\subsection{Effect of contact time}

The original ash material (MSWCA), together with the synthesized products (SZ, ISZ and UISZ), was employed for the arsenic removal studies (Fig. 4). The purpose of this study was to investigate the effects of zeolitic structure and mineralogical composition on arsenic removal efficiency and find the optimum contact time. ISZ and UISZ were much more effective for arsenate removal compared with MSWCA and SZ, which showed that iron oxides impregnating into zeolite played an important role in the arsenic removal process.

SZ is composed of crystalline hydrated aluminosilicates of sodium. The isomorphous substitution of aluminum ions for silica ions into the component polyhedra caused a residual charge on the oxygen framework, and this charge can be balanced by the adsorbed cations [27]. Ferrous ion is the appropriate candidate for the cation under ferrous sulfate solution system. On the other hand, zeolite has a well-defined and well-ordered structure that provided an ideal environment to entrap active metal complexes or metal clusters

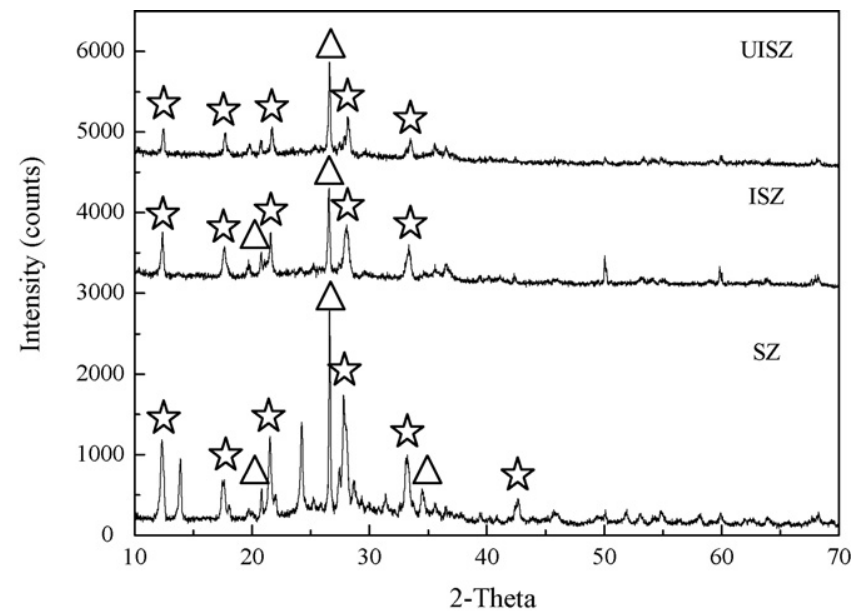

Fig. 3. X-ray diffraction patterns of SZ, ISZ and UISZ. ( $\Delta$, Z Zeolite P; $\Delta$, Quartz.)
[28]. According to a previous report, accumulation of $\mathrm{FeOOH}$ and iron(III) oxides during the iron(II) loading was identified through diffuse reflectance spectroscopy and the voltammetry of microparticles methods [29], thus the iron ion loaded on the zeolite in this study was considered to be in ferric form.

Pentavalent arsenic predominantly exists as $\mathrm{H}_{2} \mathrm{AsO}_{4}{ }^{-}$and $\mathrm{HAsO}_{4}{ }^{2-}$ anions in the studied $\mathrm{pH}(\mathrm{pH} 7.5)$. The adsorption of arsenic(V) is taking place by ion exchange where $\mathrm{OH}^{-}$ions are replaced by arsenate anions, which can be described as follows:

$\mathrm{FeOH}+\mathrm{H}_{2} \mathrm{AsO}_{4}{ }^{-} \rightarrow \mathrm{Fe}\left(\mathrm{H}_{2} \mathrm{AsO}_{4}\right)+\mathrm{OH}^{-}$

$2 \mathrm{FeOH}+\mathrm{HAsO}_{4}{ }^{2-} \rightarrow \mathrm{Fe}_{2}\left(\mathrm{HAsO}_{4}\right)+2 \mathrm{OH}^{-}$

It is suggested that the adsorption of $\mathrm{As}(\mathrm{V})$ mostly occurs at active sites on ferric oxides/hydroxide deposited on the surface and in the cavity of SZ by loading treatment. The adsorption of $\mathrm{As}(\mathrm{V})$ was enhanced with increasing the amount of these active sites, which was dependent on the effective surface area increased by ultrasonic treatment. As shown in Fig. 4, As(V) removal efficiency reached $97.3 \%$ by UISZ, doubling that by ISZ beyond $7 \mathrm{~h}$. Results also showed that modified zeolite enabled rapid removal of $\mathrm{As}(\mathrm{V})$ under these experimental conditions. From Fig. 4, it was concluded that a contact time of $7 \mathrm{~h}$ was sufficient for $\mathrm{As}(\mathrm{V})$ removal by the modified adsorbents. For their high removal efficiency of $\mathrm{As}(\mathrm{V})$, much attention in this work was paid to the ISZ and UISZ.

\subsection{Effect of $p H$}

The acidity of solution $(\mathrm{pH})$ is one of the most important parameters controlling $\mathrm{As}(\mathrm{V})$ removal from wastewater. For pentavalent arsenic, the corresponding stable species and $\mathrm{pH}$ values are: $\mathrm{H}_{3} \mathrm{AsO}_{4}(\mathrm{pH} 0.0-2.0), \mathrm{H}_{2} \mathrm{AsO}_{4}{ }^{-}$( $\left.\mathrm{pH} 2.0-7.0\right), \mathrm{HAsO}_{4}{ }^{2-}(\mathrm{pH}$ 7.0-12.0) and $\mathrm{AsO}_{4}{ }^{3-}$ ( $\left.\mathrm{pH} 12.0-14.0\right)$ [3]. Therefore, different solution $\mathrm{pH}$ determined different $\mathrm{As}(\mathrm{V})$ removal efficiency (Fig. 5).

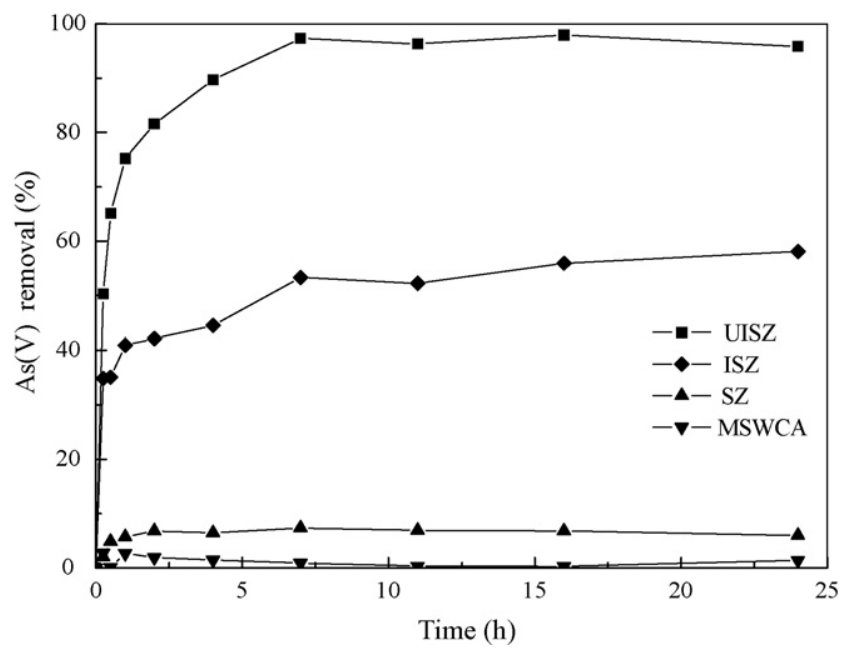

Fig. 4. Effect of contact time on $\mathrm{As}(\mathrm{V})$ removal. Reaction conditions: initial $\mathrm{As}(\mathrm{V})$ concentration $=5.0 \mathrm{mgl}^{-1}$; sorbent dose $=0.5 \mathrm{gl}^{-1} ; \mathrm{pH}=7.5$. 


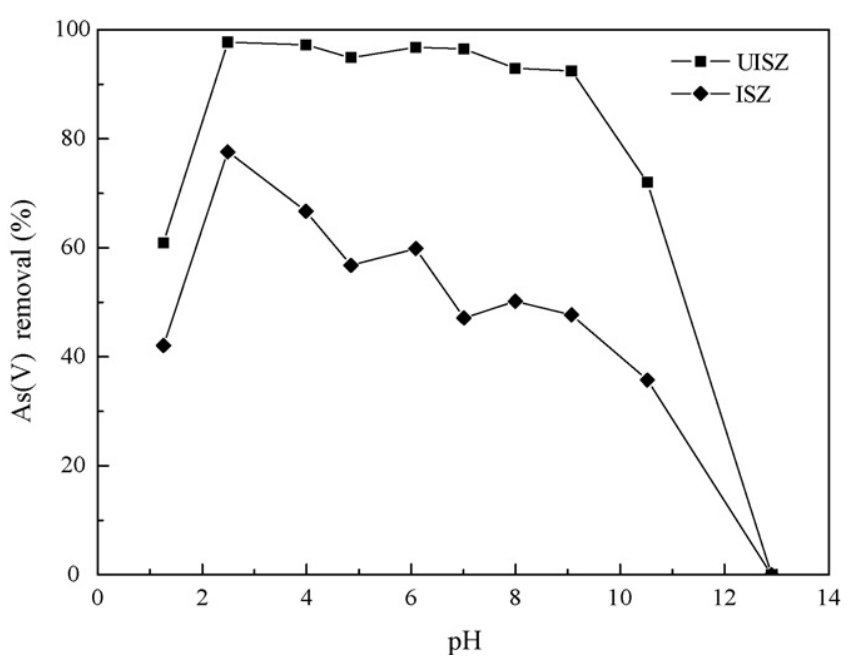

Fig. 5. Effect of initial solution $\mathrm{pH}$ on $\mathrm{As}(\mathrm{V})$ removal. Reaction conditions: initial $\mathrm{As}(\mathrm{V})$ concentration $=5.0 \mathrm{mg} \mathrm{l}^{-1}$; sorbent dose $=0.5 \mathrm{~g} \mathrm{l}^{-1}$; contact time $=7 \mathrm{~h}$.

Specifically, at $\mathrm{pH}<2.5$ or $\mathrm{pH}>10.0$, the removal efficiency of $\mathrm{As}(\mathrm{V})$ was very low for both modified zeolites. At pH range of 2.0-10.0, removal efficiency of $\mathrm{As}(\mathrm{V})$ could reach above $50 \%$. Especially, the maximum $\mathrm{As}(\mathrm{V})$ removal efficiency reached $97.8 \%$ for UISZ. While for the ISZ in the pH range of 2.0-10.0, the efficiency removal of $\mathrm{As}(\mathrm{V})$ was decreased from 80 to $50 \%$ gradually.

The different behaviors on the removal of $\mathrm{As}(\mathrm{V})$ by two adsorbents are due to the different reaction routes. As $(\mathrm{V})$ removal by modified zeolite is supposed to be mainly through two routes: affinity adsorption and reaction with iron oxides [19]. Affinity adsorption relates to the surface area of adsorbent while chemical reaction relates to the existing forms of the $\mathrm{As}(\mathrm{V})$ species, i.e., relates to the acidity of the solution. For UISZ, ultrasound-assisted modification increased the surface area and therefore, affinity adsorption and reaction with iron oxides acted together for $\mathrm{As}(\mathrm{V})$ removal. While for ISZ, direct modification didn't improve the corresponding surface area, thus the $\mathrm{pH}$ of solution was the key influence factor on the efficiency of $\mathrm{As}(\mathrm{V})$ removal. The positive charge density of adsorbent surface decreased with the increase of $\mathrm{pH}$ value, and therefore the removal efficiency of $\mathrm{As}(\mathrm{V})$ decreased due to decreasing electrostatic attraction.

\subsection{Effect of adsorbent dose}

The effect of the adsorbent dose on the removal of $\operatorname{As}(\mathrm{V})$ is shown in Fig. 6. The results indicated that the removal efficiency of $\mathrm{As}(\mathrm{V})$ increased with the increase of adsorbent dose, due to the greater availability of the exchangeable sites or surface area at high amounts of the adsorbent. It was observed that $1 \mathrm{~g} \mathrm{l}^{-1}$ of UISZ or $2 \mathrm{gl}^{-1}$ of ISZ was sufficient to reduce the concentration of $\mathrm{As}(\mathrm{V})$ below $50 \mu \mathrm{gl}^{-1}$ in aqueous system. The experimental data (Fig. 6) showed that the $\mathrm{As}(\mathrm{V})$ removal efficiency of UISZ was higher than that of ISZ. These results indicate that UISZ is more effective than ISZ for the adsorption of $\mathrm{As}(\mathrm{V})$. Arsenic removal was not effective at lower solid to liquid ratios, which may be due to insufficient capacity for ligand exchange on the modified zeolites.

\subsection{Effect of initial As(V) concentration}

Arsenic solution at different concentration of $0.5,1.0,5.0,10.0$, 20.0, 25.0 and $30.0 \mathrm{mg} \mathrm{l}^{-1}$ were treated with $0.5 \mathrm{gl}^{-1}$ of adsorbent at $\mathrm{pH}$ 7.5. Fig. 7 shows the effect of varying arsenic concentration against the removal efficiency of $\mathrm{As}(\mathrm{V})$. As expected, the removal efficiency of $\mathrm{As}(\mathrm{V})$ decreased with increasing concentration of

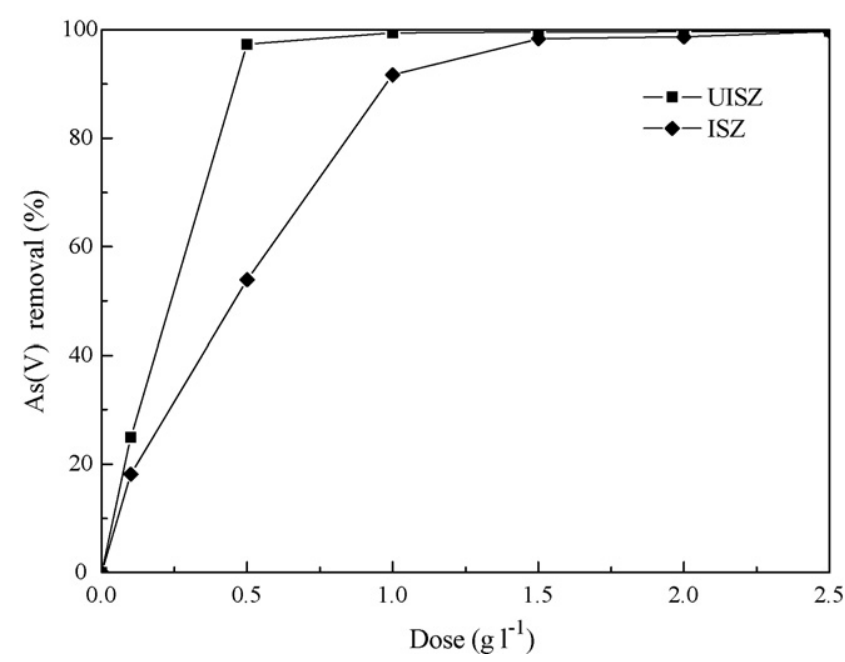

Fig. 6. Effect of sorbent dose on $\mathrm{As}(\mathrm{V})$ removal. Reaction conditions: initial $\mathrm{As}(\mathrm{V})$ concentration $=5.0 \mathrm{mgl}^{-1} ;$ contact time $=7 \mathrm{~h} ; \mathrm{pH}=7.5$.

adsorbent, which indicated that the adsorption depended upon the availability of binding sites for $\mathrm{As}(\mathrm{V})$ ions. When the initial $\mathrm{As}(\mathrm{V})$ concentrations were 0.5 and $1.0 \mathrm{mg} \mathrm{l}^{-1}$, the removal efficiency of As $(\mathrm{V})$ could reach above $99 \%$ and the final concentration for both adsorbents was decreased below $10 \mu \mathrm{gl}^{-1}$. When the initial $\mathrm{As}(\mathrm{V})$ concentration was $5.0 \mathrm{mg} \mathrm{l}^{-1}$, the $\mathrm{As}(\mathrm{V})$ removal efficiency reached $97 \%$ for UISZ and the final concentration of $\mathrm{As}(\mathrm{V})$ was still below $50 \mu \mathrm{gl}^{-1}$, while for ISZ the removal efficiency of As(V) decreased to $53 \%$. When the initial concentration was above $10.0 \mathrm{mg} \mathrm{l}^{-1}$, removal efficiency of $\mathrm{As}(\mathrm{V})$ was less than $50 \%$ within $7 \mathrm{~h}$ reaction time for both adsorbents.

The adsorption data plotted with both the Langmuir and Freundlich isotherm models since they are simple and classical models to describe the equilibrium between metal ions adsorbed onto adsorbent and metal ions in solution at a constant temperature (Fig. 8). The fitting constants for the Langmuir and Freundlich isotherm models along with correlated coefficients $\left(R^{2}\right)$ are summarized in Table 1. As can be seen from Fig. 8, the adsorption data was well fit by the Langmuir isotherm model. The $R^{2}$ values obtained for the Langmuir isotherm were above 0.92 , indicating a very good mathematical fitness. Consequently, the sorption of $\mathrm{As}(\mathrm{V})$ ions onto zeolite occurred on homogeneous surface by monolayer sorption without interaction between sorbed molecules. The data

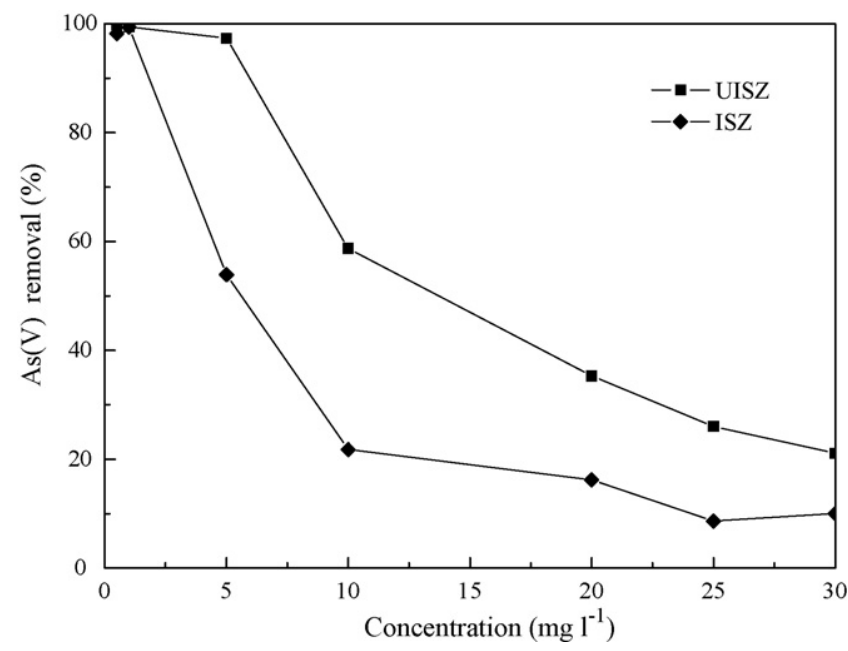

Fig. 7. Effect of initial arsenic concentration on $\mathrm{As}(\mathrm{V})$ removal. Reaction conditions: sorbent dose $=0.5 \mathrm{gl}^{-1}$; contact time $=7 \mathrm{~h} ; \mathrm{pH}=7.5$. 


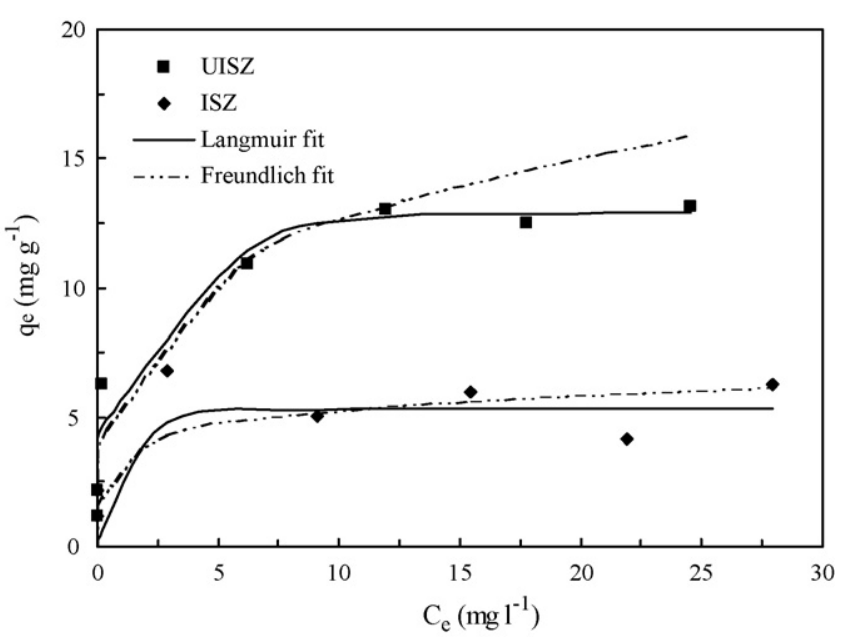

Fig. 8. Adsorption isotherms of $\mathrm{As}(\mathrm{V})$ on ISZ and UISZ at $25 \pm 0.5^{\circ} \mathrm{C}$. Reaction conditions: sorbent dose $=0.5 \mathrm{gl}^{-1}$; contact time $=7 \mathrm{~h} ; \mathrm{pH}=7.5$.

in Table 1 revealed that the adsorption capacity $\left(Q_{m}\right)$ of the UISZ was much higher $\left(13.04 \mathrm{mg} \mathrm{g}^{-1}\right)$ than that of ISZ $\left(5.37 \mathrm{mg} \mathrm{g}^{-1}\right)$ [30]. Freundlich adsorption isotherm is a curve relating the concentration of a solute on the surface of an adsorbent, to the concentration of the solute in the liquid with which it is in contact. Langmuir adsorption isotherm describes quantitatively the build up of a layer of molecules on an adsorbent surface as a function the concentration of the adsorbed material in the liquid is which it is in contact. So the Freundlich isotherm was not very favorable under wide concentration range (0-30 $\left.\mathrm{mg} \mathrm{l}^{-1}\right)$ [30].

\subsection{Leaching tests}

The evaluation of the leaching potential of spent adsorbents is important in assessing their possible environmental impacts. The

Table 1

Langmuir and Freundlich isotherm constants

\begin{tabular}{lll}
\hline & ISZ & UISZ \\
\hline Langmuir $\left(\frac{C_{\mathrm{e}}}{q_{\mathrm{e}}}=\frac{C_{\mathrm{e}}}{Q_{\mathrm{m}}}+\frac{1}{b Q_{\mathrm{m}}}\right) \mathrm{a}$ & & \\
$Q_{\mathrm{m}}\left(\mathrm{mg} \mathrm{g}^{-1}\right)$ & 5.37 & 13.04 \\
$b\left(\mathrm{mg}^{-1}\right)$ & 7.60 & 3.29 \\
$R^{2}$ & 0.9274 & 0.9974 \\
Freundlich $\left(\log q_{\mathrm{e}}=\log K_{\mathrm{F}}+\frac{1}{n} \log C_{\mathrm{e}}\right)^{\mathrm{a}}$ & \\
$K_{\mathrm{F}}\left(\mathrm{mgg} \mathrm{g}^{-1}\right)$ & 3.65 & 6.79 \\
$n$ & 6.32 & 1.34 \\
$R^{2}$ & 0.7690 & 0.7458 \\
\hline
\end{tabular}

a $C_{\mathrm{e}}\left(\mathrm{mgl}^{-1}\right)$ : equilibrium arsenic concentration; $q_{\mathrm{e}}\left(\mathrm{mg} \mathrm{g}^{-1}\right)$ : arsenic adsorption at equilibrium concentration; $Q_{\mathrm{m}}, b, K_{\mathrm{F}}, n$ : adsorption constants.

Table 2

Leaching test of spend adsorbent and the identification standard ( $\mathrm{mg} \mathrm{l}^{-1}$ )

\begin{tabular}{lllc}
\hline Metal & ISZ & UISZ & US EPA standarda \\
\hline As & 1.960 & 2.320 & 5 \\
$\mathrm{Ag}$ & $\mathrm{ND}^{\mathrm{b}}$ & $\mathrm{ND}$ & 5 \\
$\mathrm{Ba}$ & 0.014 & 0.016 & 1 \\
$\mathrm{Cr}$ & 0.039 & 0.039 & 5 \\
$\mathrm{Cu}$ & 0.045 & 0.062 & 100 \\
$\mathrm{Ni}$ & 0.032 & 0.049 & 100 \\
$\mathrm{~Pb}$ & 0.036 & 0.041 & 5 \\
$\mathrm{Cd}$ & $\mathrm{ND}$ & $\mathrm{ND}$ & 1 \\
\hline
\end{tabular}

a US EPA maximum limits for disposal of waste to landfill [31].

b ND: not detected.
TCLP method was employed to classify the spent adsorbents as hazardous or inert waste. The leaching results are listed in Table 2. Among metals, $\mathrm{Cd}$ and $\mathrm{Ag}$ were not detected in the leachate from spent adsorbents. It was evident that the concentration of metals in leachate was higher from UISZ than from ISZ. In general, metal concentration in leachate from spent adsorbents was found to be less than maximum limits stated by US EPA [31]. Therefore, for spent UISZ and ISZ, they will be safe, and can be directly landfilled, as the concentrations of heavy metals in their leachates are much lower than the standard.

\section{Conclusions}

The results of this study demonstrated that waste ash from MSW and coal co-combustion power plant was a special type of waste material that could be used for high quality adsorbent development. Of the two types of adsorbents synthesized, ISZ and UISZ presented effective $A s(V)$ adsorption ability, especially suitable for removal of $\mathrm{As}(\mathrm{V})$ in low concentration. The $\mathrm{As}(\mathrm{V})$ adsorption capacities for UISZ and ISZ were 13.04 and $5.37 \mathrm{mg} \mathrm{g}^{-1}$, respectively. Comparatively, UISZ showed greater adsorption affinity for the $\mathrm{As}(\mathrm{V})$ than ISZ, which showed that ultrasound irradiation was a good approach for impregnating iron ions into the zeolite pores. Removal $\mathrm{As}(\mathrm{V})$ by ISZ was highly $\mathrm{pH}$ sensitive and high removal efficiency was achieved at $\mathrm{pH} 2.5$, while UISZ was $\mathrm{pH}$ independent and could be effectively employed to aqueous systems at a $\mathrm{pH}$ range of 2.0-10.0 without $\mathrm{pH}$ adjustment. The adsorption isotherm data could be well described by Langmuir isotherm, indicating that the adsorption of $\mathrm{As}(\mathrm{V})$ ions on UISZ and ISZ occurred on homogeneous surface by monolayer sorption without interaction between sorbed molecules. These results demonstrated that the UISZ was an excellent low-cost sorbent for As(V) removal from aqueous system.

\section{Acknowledgements}

This work was financially supported, in part, by the National Basic Research Program of China (2007CB407303) and National Natural Science Foundation of China (20777084).

\section{References}

[1] C.K. Jain, I. Ali, Arsenic: occurrence, toxicity and speciation techniques, Water Res. 34 (2000) 4304-4312.

[2] Chinese Environment Protection Association, The Collection of Chinese National Standard, Chinese National Standard Press, Beijing, 1996, p. 272 (in Chinese).

[3] A.J. Bard, R. Parsons, J. Jordan, Standard Potentials in Aqueous Solutions, Marcel Dekker, New York, 1985.

[4] H. Guo, D. Stüben, Z. Berner, Adsorption of arsenic(III) and arsenic(V) from groundwater using natural siderite as the adsorbent, J. Colloid Interface Sci. 315 (2007) 47-53.

[5] J. Kim, M.M. Benjamin, Modeling a novel ion exchange process for arsenic and nitrate removal, Water Res. 38 (2004) 2053-2062.

[6] T.J.Sorg, G.S. Logsdon, Treatment technology to meet the interim primary drinking water regulation for inorganics: part 2, J. Am. Water Works Assoc. 70 (1978) 379-392.

[7] W. Driehaus, M. Jekal, U. Hildebrand, Granular ferric hydroxide: a novel adsorbent for the removal of arsenic from natural water, J. Water SRT 47 (1998) 30-35.

[8] K. Košutić, L. Furač, L. Sipos, B. Kunst, Removal of arsenic and pesticides from drinking water by nanofiltration membranes, Sep. Purif. Technol. 42 (2005) 137-144.

[9] A.I. Zouboulis, I.A. Katsoyiannis, Recent advances in the bioremediation of arsenic-contaminated groundwaters, Environ. Int. 31 (2005) 213-219.

[10] F.S. Zhang, H. Itoh, Photocatalytic oxidation and removal of arsenite from water using slag-iron oxide- $\mathrm{TiO}_{2}$ adsorbent, Chemosphere 65 (2006) 125-131.

[11] S. Xia, B. Dong, Q. Zhang, B. Xu, N. Gao, C. Causseranda, Study of arsenic removal by nanofiltration and its application in China, Desalination 204 (2007) 374-379.

[12] L.V. Rajakoviv, The sorption of arsenic onto activated carbon impregnated with metallic silver and copper, Sep. Sci. Technol. 27 (1992) 1423-1433.

[13] T.F. Lin, J.K. Wu, Adsorption of arsenite and arsenate within activated alumina grains: equilibrium and kinetics, Water Res. 35 (2001) 2049-2057. 
[14] K.P. Raven, A. Jain, R.H. Loeppert, Arsenite and arsenate adsorption on Ferrihydrite: kinetics, equilibrium and adsorption envelopes, Environ. Sci. Technol. 32 (1998) 344-349.

[15] S. Tokunaga, S.A. Wasay, S.-W. Park, Removal of arsenic(V) ion from aqueous solutions by lanthanum compounds, Water Sci. Technol. 35 (1997) 71-78.

[16] B.A. Manning, S.E. Fendorf, S. Goldberg, Surface structures and stability of arsenic (III) on goethite: spectroscopic evidence for inner-sphere complexes, Environ. Sci. Technol. 32 (1998) 2383-2388.

[17] R.C. Vaishya, S.K. Gupta, Arsenic removal from groundwater by iron impregnated sand, J. Environ. Eng. 129 (2003) 89-92.

[18] C.P. Huang, L.M. Vane, Enhancing $\mathrm{As}^{5+}$ removal by a $\mathrm{Fe}^{2+}$-treated activated carbon, J. WPCF 61 (1989) 1596-1603.

[19] F.S. Zhang, H. Itoh, Iron oxide-loaded slag for arsenic removal from aqueous system, Chemosphere 60 (2005) 319-325

[20] Y. Fan, F.S. Zhang, J. Zhu, Z. Liu, Effective utilization of waste ash from MSW and coal co-combustion power plant-zeolite synthesis, J. Hazard. Mater. 153 (2008) 382-388.

[21] U.S. EPA, Test Methods for Evaluating Solid Waste, SW-846, third ed., Office of Solid Waste, Washington, DC, 1996

[22] M.P. Elizalde-González, J. Mattusch, R. Wennrich, P. Morgenstern, Uptake of arsenite and arsenate by clinoptilolite-rich tuffs, Microporous Mesoporous Mater. 46 (2001) 277-286.
[23] G.V. Tsitsishvili, T.G. Andronikashvili, G.N. Kirov, L.D. Filizova, Natural Zeolites, Ellis Horwood Press, New York, 1992.

[24] V.M. Malhotra, A.A. Ogloza, FTIR spectra of hydroxyls and dehydroxylation kinetics mechanism in montmorillonite, Phys. Chem. Miner. 16 (1989) 386393.

[25] R.M. Cornell, U. Schwertmann, The Iron Oxides, VCH Verlagsgesellschaft, Weinheim, VCH Publishers, New York, 1996.

[26] L. Zhu, H. Zhang, W. Li, H. Liu, Investigation of zinc powder modified by ultrasonic impregnation of rare earth lanthanum, Appl. Surf. Sci. 253 (2007) 9443-9449.

[27] G. Purna Chandra Rao, S. Satyaveni, A. Ramesh, K. Seshaiah, K.S.N. Murthy, N.V. Choudary, Sorption of cadmium and zinc from aqueous solutions by zeolite $4 \mathrm{~A}$, zeolite 13X and bentonite, J. Environ. Manag. 81 (2006) 265-272.

[28] S.M. Drechsel, R.C.K. Kaminski, S. Nakagaki, F. Wypych, Encapsulation of Fe(III) and $\mathrm{Cu}(\mathrm{II})$ complexes in NaY zeolite, J. Colloid Interface Sci. 277 (2004) 138145.

[29] B. Doušová, T. Grygar, A. Martaus, L. Fuitová, D. Koloušek, V. Machovič, Sorption of $\mathrm{As}^{\mathrm{V}}$ on aluminosilicates treated with $\mathrm{Fe}^{\mathrm{II}}$ nanoparticles, J. Colloid Interface Sci. 302 (2006) 424-431.

[30] D. Mohan, C.U. Pittman Jr., Arsenic removal from water/wastewater using adsorbents-a critical review, J. Hazard. Mater. 142 (2007) 1-53.

[31] US EPA, Toxicity Test Procedure, Federal Register, 40 CFR, Part 261.24, 1980. 